\title{
Inovação em serviços de saúde no Brasil: análise dos casos premiados no Concurso de Inovação na Administração Pública Federal
}

\author{
Vicente da Rocha Soares Ferreira \\ Universidade Federal de Goiás \\ Estela Najberg \\ Universidade Federal de Goiás \\ Cintia Bragheto Ferreira \\ Universidade Federal de Goiás \\ Nelson Bezerra Barbosa \\ Secretaria de Estado da Saúde de Goiás \\ Cândido Borges \\ Universidade Federal de Goiás
}

\begin{abstract}
Este trabalho trata da inovação no setor público de saúde, com o objetivo de descrever e analisar o perfil das experiências que ganharam o Prêmio Inovação na Administração Pública Federal, entre 1995 e 2011. O estudo é do tipo qualitativo-descritivo e levantou 19 casos na área de saúde, coletados no site da Escola Nacional de Administração Pública (Enap). Os casos foram analisados de acordo com as dimensões: identificação dos casos, objetivos, tipo, abrangência e resultados do trabalho. Os resultados apontam inovações incrementais, com predominância do tipo de inovação de processo e serviços, com foco na busca de eficiência operacional, e tiveram abrangência nacional. Sugerem-se medidas de incentivos governamentais à inovação no setor público, além de uma agenda de pesquisa de inovação no setor público de saúde.
\end{abstract}

Palavras-chave: inovação; saúde; serviço público.

La innovación en el cuidado de la salud en Brasil: análisis de casos premiados en el Concurso de Innovación en la Administración Pública Federal

En este trabajo se trata de la innovación en el sector público de la salud con el objetivo de describir y analizar el perfil de las experiencias que han ganado el Premio de Innovación en la Administración

DOI: http://dx.doi.org/10.1590/0034-76121602

Artigo recebido em 16 jun. 2013 e aceito em 25 abr. 2014. 
Pública Federal, entre 1995 y 2011. El estudio es del tipo descriptivo cualitativo y analizó 19 casos en el área de la salud, recogidos en el sitio de Escola Nacional de Administração Pública (Enap). Los casos fueron analizados de acuerdo a las dimensiones: identificación de los casos, los objetivos, tipo, alcance y resultados del trabajo. Los resultados muestran innovaciones incrementales, con predominio de la innovación de procesos y servicios, centrándose en la búsqueda de la eficiencia operativa, había cobertura nacional. Se sugieren medidas de incentivos gubernamentales a la innovación en el sector público, además de una agenda de investigación de la innovación en el sector público de salud.

Palabras clave: innovación; salud; servicio público.

Innovation in health services in Brazil: an analysis of the cases awarded in the Innovation Competition at the Federal Public Administration

This paper addresses innovation in the public health sector, aiming to describe and analyze the profiles of the cases that have won the Innovation Award in Federal Public Administration, between 1995 and 2011. The study is of a qualitative and descriptive nature, and it was carried out by analyzing 19 cases in healthcare, collected from the National School of Public Administration (Enap) website. These cases were analyzed according to the following dimensions: identification of cases, objectives, type, scope and results of the work. The results show incremental innovations, predominantly in those types of innovation of processes and services, focusing on the search for operational efficiency, and those cases had national coverage. Finally, we suggest measures for governmental incentives for innovation in the public sector, and a research agenda for innovation in the public health sector.

KEYWords: innovation; health; public service.

\section{Introdução}

O setor de saúde é representativo do ponto de vista econômico, considerando-se que o consumo dos serviços de saúde no Brasil representou, em 2007, 8,2\% do Produto Interno Bruto (PIB), de acordo com dados do Instituto Brasileiro de Geografia e Estatística (IBGE) daquele ano. Somente no setor de saúde pública são 140 milhões de usuários que dependem exclusivamente do Sistema Único de Saúde (SUS) (Brasil, 2009a), ou seja, é muito significativo quantitativamente, bem como nos desafios porque a qualidade dos serviços de saúde ainda deixa a desejar. Como exemplos, registrem-se fatos como as repetidas epidemias de dengue no país, ou alguns dados como as mais de 4 mil mortes por ano das vítimas de tuberculose (Brasil, 2009b).

O envelhecimento da população no Brasil (Brasil, 2009a), fato que preocupa também outros países (Hennala, Parjanen e Uotila, 2011; Cunningham, 2005), somado ao aumento de sua conscientização, deixa o serviço público mais pressionado a atender adequadamente as necessidades de saúde dessa população. No entanto, o investimento público federal em serviços de saúde não tem crescido na proporção do PIB nos últimos 15 anos (Brasil, 2009a), o que enseja a necessidade de respostas novas do setor às suas demandas crescentes. 
Uma das formas de responder a esses desafios passa pela necessidade de inovações, não só tecnológicas, e suas variantes de produto, processo e serviços, mas também organizacionais, gerenciais e sociais (Beinare e McCarthy, 2011; Halvorsen et al., 2005; Røste, 2005). Isso tornaria a prestação desses serviços mais eficiente e eficaz, o que levaria a outra demanda da sociedade que é a boa gestão dos recursos públicos, o que significa responder de forma diferente a essa população que tradicionalmente se serve da estrutura de serviços prestados pelo Estado.

A prestação de serviços de qualidade é pressuposto de cidadania, e tal situação-objetivo pode ser alcançada por controle social efetivo e por transparência na utilização dos recursos, uma vez que a vocalização de interesses dos usuários deveria ser uma importante referência para a tomada de decisões. Os estudos em inovação tradicionalmente se voltam para o setor empresarial, mais especificamente para o setor industrial, o que não se aplica linearmente ao setor público, mesmo que essa seja essencial para capacitar o governo para o enfrentamento de seus desafios (Salge, 2010; Halvorsen et al., 2005). Uma das explicações para os limites da aplicação dos modelos de inovação empresarial no setor público reside na diferença entre o contexto regulamentar que envolve a administração pública derivada do tipo de propriedade, da natureza e dos objetivos de uma organização pública diante da outra do setor privado. Segundo Røste (2005), as condições legais, as normas e a cultura do contexto institucional representam importantes incentivos ou restrições ao processo de inovação.

Sabe-se que o ambiente que favorece a inovação é aquele que proporciona liberdade para seus agentes e incentiva o desenvolvimento de novas práticas pelos seus colaboradores (Tidd, Bessant e Pavitt, 2008). Tal ambiente nem sempre é encontrado na administração pública, pois, enquanto o setor privado pode praticar tudo aquilo que não esteja proibido, o setor público só pode praticar aquilo que esteja devidamente normatizado, e, no caso dos serviços de saúde pública, existe um excesso de regulamentação (Santos e Andrade, 2009).

Contudo, ainda é incipiente a pesquisa sobre as práticas da inovação em gestão no interior dos sistemas de serviços públicos (Walker, Damanpour e Devece, 2010; Gallouj e Windrum, 2009; Salazar e Holbrook, 2004), mas de fato existem práticas de inovação nesses serviços, como aquelas submetidas e premiadas no Concurso de Inovação na Administração Pública Federal, promovido anualmente pela Escola Nacional de Administração Pública, há 16 anos. Assim, o objetivo deste estudo é descrever e analisar o perfil das experiências de inovação no setor de saúde no Brasil que ganharam esse Prêmio nas 16 edições do referido concurso, compreendidas no período entre 1995 e 2011. Com isso, espera-se contribuir para a difusão de pesquisas sobre inovação nos serviços de saúde no Brasil além de abrir caminho para uma agenda de pesquisa nessa área.

\section{Inovação no setor público}

O processo de inovação no setor público tem uma longa história internacionalmente (Halvorsen et al., 2005). No Brasil também não é recente, mas essa denominação aparece apenas nos 
anos de 1980, com as experiências de administrações municipais que encontravam soluções consideradas inovadoras para superação de problemas locais e, para isso, contavam com a participação popular na construção de políticas. Naquela época, dava-se maior ênfase à natureza democrática das mudanças do que propriamente ao processo de mudança ou ao fato de ocorrer uma inovação (Farah, 2010).

Atualmente, a expressão inovação já se difundiu na área pública, assumindo diferentes sentidos, ora significando processos de mudanças voltados à busca da gestão eficiente, ora significando a democratização da ação estatal, tanto no aumento do volume de serviços oferecidos à população quanto na ampliação da participação popular na formulação, implementação e controle das políticas públicas (Farah, 2010).

Na perspectiva da inovação como busca pela eficiência de gestão, podem ser observados elementos da nova gestão pública que transpõem a ideia de competição do setor privado para o setor público, procurando incorporar padrões gerenciais com a utilização de métodos e técnicas desenvolvidos pelo setor privado (Klering e Andrade, 2006). Essa vertente da inovação emerge no bojo das reformas do Estado, a partir do final da década de 1970 (Farah, 2010). Já na perspectiva da democratização e da participação social na gestão do Estado, observamse aspectos da inovação social (Beinare e McCarthy, 2011). Esta significa uma ampliação do setor público que envolve mudanças de valores sociais no nível institucional, tais como o de cidadania e inclusão, bem como a integração de novos atores no processo decisório e de implementação das ações públicas no nível organizacional (Klering e Andrade, 2006).

As reformas do Estado referidas alcançam o Brasil nos anos de 1990 e têm como discurso a crítica à rigidez burocrática e a necessidade de mudanças, com a incorporação dos princípios da nova gestão pública. No conjunto dessas reformas do aparelho do Estado e da administração pública, é lançado, em 1996, o Concurso de Inovação na gestão pública federal pela Escola Nacional de Administração Pública (Enap), privilegiando a inovação da administração pública na dimensão gerencial da mudança (Farah, 2006). Os princípios que nortearam a reforma do Estado, assim como a dimensão de inovação adotada nesse processo de mudança, parece que têm influenciado e incentivado o desenvolvimento da inovação no setor público. O rumo que tomam os processos de reformas e, em seu interior, as experiências de inovação também são encontrados em nível internacional, como é possível observar na literatura.

De forma geral, a inovação pode ser definida como a geração, desenvolvimento e implementação de novas ideias, objetos ou práticas por pessoas que, ao longo do tempo, se engajam em relações com outras dentro de um contexto institucional. Especificamente, pode ser um novo processo, uma nova estrutura organizacional ou sistema administrativo, um novo plano ou programa pertencentes a membros de uma organização (Halvorsen, 2005; Røste, 2005; Van de Ven, 1986). Outra definição é a do Manual de Oslo, para o qual a inovação significa:

a implementação de um produto (bem ou serviço) novo ou significativamente melhorado, ou um processo, ou um novo método de marketing, ou um novo método organizacional nas práticas de negócios, na organização do local de trabalho ou nas relações externas (OCDE, 2006:65). 
Quanto ao tipo, o Manual de Oslo (2006) indica que uma inovação pode ser de produto, processo, organizacional ou de marketing. Uma inovação de produto é a introdução de um produto ou serviço novo ou significativamente aperfeiçoado em suas características ou usos. Uma inovação de processo é a implementação de um novo método de produção ou distribuição ou seu aperfeiçoamento. A inovação de marketing é a implementação de um método de marketing novo com mudanças significativas na concepção do produto ou em sua embalagem, no posicionamento do produto, em sua promoção ou na fixação de preços. E a inovação organizacional é a implementação de um novo método organizacional nas práticas de negócios de uma empresa, na organização de seu local de trabalho ou em suas relações externas. Tidd, Bessant e Pavitt (2008) acrescentam ainda a inovação de posição, em que há mudanças no contexto no qual produtos e serviços são introduzidos (relançamento de um produto com uma nova função); e a inovação de paradigma, com mudanças nos modelos mentais subjacentes que moldam o que a organização faz (a provisão de seguros on-line para companhias aéreas de baixo custo).

Esses conceitos estão próximos daqueles primeiramente desenvolvidos por Schumpeter, que são os tipos organizacional, produto, mercado e processo de input de inovações (Gallouj e Djellal, 2010). A inovação pode ainda ser incremental ou radical. Incremental quando a mudança não representa algo totalmente novo, e radical quando a "inovação representa algo descontínuo, algo complemente novo ou uma resposta a condições profundamente alteradas” (Tidd, Bessant e Pavitt, 2008:33).

Tidd, Bessant e Pavitt (2008) apresentam um modelo de processo de gestão de inovação constituído de três fases, que eles chamam de "buscar", "selecionar" e "implementar". O processo de inovação tem início com a busca de vários indícios de oportunidades que podem estar na tecnologia, no mercado, no comportamento competitivo, nas mudanças da política ou no ambiente regulador, em novas tendências sociais, dentre outros. Na fase de seleção, a empresa precisa se perguntar o que pode ser feito, desenvolvendo um plano que não a engesse, mas se pautando pelo jogo competitivo do mercado. Um plano que articule como elas imaginam que a inovação pode auxiliar sua sobrevivência e crescimento. Já a fase de implementação, constituída das subfases de "adquirir", "executar", "lançar" e "sustentar", envolve conhecimento novo e aquele já disponível no mercado para oferecer uma solução para o problema da inovação. Segundo os autores, nessa fase devem-se não só definir os recursos a serem aplicados no processo de inovação, mas como esses devem ser aplicados.

E no setor público, como esse processo pode ser compreendido? Como uma mudança substancial, qualitativa ou quantitativa nas práticas anteriores, uma nova estrutura organizacional ou sistema administrativo, um novo plano ou programa pertencente a membros de uma organização, resultando em um novo produto, serviço, ou prática que é nova para o estado da arte, ou nova, pelo menos, para o contexto organizacional (Beinare e McCarthy, 2011; Damanpour e Wischnevsky, 2006; Spink, 2006; Røste, 2005; O’Toole, 1997).

Salazar e Holbrook (2004) afirmam que parece fazer sentido a inclusão do setor público nas pesquisas sobre inovação, especialmente naquelas sobre a inovação em serviços, já que o setor público é um importante fornecedor de serviços. Para Vargas (2006), discutir a inovação 
no setor público é abordar, em grande medida, inovação em serviços, campo ainda não consolidado. Como em qualquer setor de serviços, ele pode melhorar a qualidade do que é ofertado à população usuária, com efeitos sobre os benefícios sociais aportados, mas também sobre a produtividade, que é um produto econômico. Os gestores de serviços públicos precisam inovar tanto para melhorar a eficiência quanto para aumentar a satisfação do usuário do serviço. Earl (2002) afirma, com base em estatísticas canadenses, que naquele país o setor público é muito inovador e lidera as mudanças organizacionais e tecnológicas. E Røste (2005) completa que a inovação é importante para o setor público por várias razões, dentre elas o processo de regulação e o financiamento para incentivar a inovação.

Hennala, Parjanen e Uotila (2011), em um estudo sobre a prestação de serviços públicos na Finlândia, afirmam que o setor público, em função do envelhecimento da população, está prestes a enfrentar muitos desafios com o aumento da demanda por serviços públicos para essa população. E lá o serviço público é responsável, em grande parte, pela prestação de serviços de bem-estar social. Isso, no entanto, exige abertura da organização para a participação efetiva dos usuários no desenvolvimento dos serviços de seu interesse, o que parece lógico, já que o serviço é produzido na interface com o usuário (Gallouj e Savona, 2009).

Salazar e Holbrook (2004), ao estudarem as pesquisas sobre inovação, afirmam que tanto o setor privado quanto o setor público fazem inovação, mas questionam por que as pesquisas de inovação ignoram o setor público. Em seu trabalho, chamam a atenção para o fato de pesquisas anteriores sobre a inovação, em setores fortemente regulamentados no Canadá, indicarem que o setor público é tão inovador quanto o setor privado, No entanto, o Centro de Pesquisa em Política de Ciência e Tecnologia, da Simon Fraser University, realizou um estudopiloto no serviço público federal canadense sobre atividades de inovação tecnológica e, em seus resultados, não ficou evidente se as unidades pesquisadas tinham de fato adotado novas tecnologias para melhorar a eficiência ou aumentar o nível dos serviços que oferecem como era esperado. Esses autores sugerem que novas pesquisas precisariam ser desenvolvidas para averiguar se há inovação no setor público.

Ainda sobre a gestão da inovação no setor público, Walker, Damanpour e Devece (2010) afirmam que, mesmo sendo um tema muito presente na literatura, por sua influência no desempenho das organizações, existem poucas pesquisas no setor público sobre essa temática. Com base na perspectiva da nova gestão pública, os autores analisaram dados de experiências do setor público local na Inglaterra, com o objetivo de encontrar uma relação entre gestão da inovação e melhoria de desempenho da organização. Mas, mesmo encontrando aspectos positivos da gestão da inovação no desempenho organizacional no setor público, destacam que esses impactos positivos são mediados pelo desempenho da gerência. Os autores não mencionam se a estrutura própria do setor público seria um empecilho ou um facilitador da gestão da inovação. No entanto, Røste (2005) aponta que as condições legais, as normas e a cultura do contexto institucional representam importantes incentivos ou restrições ao processo de inovação.

Salge (2010) afirma que o governo britânico considera a inovação no serviço público essencial para capacitar o governo a enfrentar os desafios do século XXI. Beinare e McCarthy 
(2011) destacam que a inovação tem ocupado de forma crescente o setor público de saúde, construindo-se, com os usuários e outros interessados, novas possibilidades de gestão em saúde, demarcando assim seu papel social, ao invés de interesses puramente comerciais. No campo da saúde, portanto, as organizações sociais podem ter papéis de desenvolvimento de inovações e organização para as necessidades que não podem ser satisfatoriamente oferecidas somente pelo mercado.

Na Europa, essas organizações podem enfrentar esse desafio e promover a inovação social por meio de investigações de suas práticas, servindo assim aos cidadãos europeus e fortalecendo a inovação na União Europeia (Beinare e McCarthy, 2011). No Brasil, esse processo tem ocorrido desde a década de 1990, com essas organizações fazendo contratos de gestão de serviços de saúde com o setor público, especialmente em parcerias com os estados, processo ainda não consolidado aqui.

O que se percebe é que a inovação, em se tratando do setor público, pode ser considerada qualquer ação que suplante um estado anterior da ação governamental, seja em uma ação meramente administrativa, com a reestruturação ou criação de novos métodos ou processos de trabalho, por exemplo, seja em políticas públicas que possam transformar uma determinada realidade social de um jeito novo, ou mesmo de forma menos onerosa, portanto mais eficiente e eficaz. Pode-se afirmar, ainda, o setor público como esfera indutora de inovações no setor privado, mesmo que essa inovação se restrinja ao campo da relação governo-setor privado (Moreira e Vargas, 2009).

Assim, nos serviços públicos de saúde, em especial no SUS, existe um espaço considerável para a promoção de inovação em seu interior, tendo-se em vista que a concepção dessa política já é considerada como inovadora (Santos e Andrade, 2009). Em pesquisa realizada em hospitais universitários no Brasil e na Espanha, que avaliou a percepção dos profissionais de saúde sobre a utilização do prontuário eletrônico como instrumento de gestão hospitalar, Farias e colaboradores (2011) destacam que essa ferramenta representou uma inovação administrativa significativa na visão dos gestores do sistema e de seus usuários para os controles de trabalho, de custos e de informações na administração hospitalar, o que mostra que até inovações aparentemente de pouca expressão representam, em determinadas organizações, algo muito valioso.

A despeito de a pesquisa de Farias e colaboradores (2011) ser no ambiente hospitalar, esta é uma inovação com desdobramento para todos os níveis do sistema, pois introduz um instrumento de uso compartilhado entre os profissionais de saúde, desde a Estratégia de Saúde da Família até o hospital terciário.

\section{Inovação no setor de saúde}

Inovação no serviço público é um processo complexo pela presença de múltiplos atores com interesses divergentes. No setor de saúde, além de complexidade, têm-se necessidade e urgência pelos desafios que se apresentam em muitos países (Beinare e McCarthy, 2011; Cunnin- 
gham, 2005). No Brasil, a transição demográfica, marcada pelo forte processo de urbanização e envelhecimento populacional, bem como a chamada transição epidemiológica, representada pelo aumento da prevalência das doenças crônicas não transmissíveis, têm representado um enorme desafio aos sistemas e serviços de saúde. A esse desafio, o Estado brasileiro apresentou como resposta a decisão de implantação do Sistema Único de Saúde.

A escolha por um modelo público e universal sinaliza para a primeira grande inovação no setor, considerando que até então o que existia era um sistema previdenciário, em que o acesso a serviços de saúde oferecidos pela rede pública estava condicionado ao pagamento de contribuição para o sistema. Os serviços de saúde, portanto, estavam organizados na base de um mix de sistema meritocrático e residual, ou seja, os que estavam formalmente inseridos no mercado de trabalho tinham direito a consumir ações e serviços médicos hospitalares, na rede do antigo Instituto Nacional de Assistência Médica e Promoção Social (Inamps) ou na rede conveniada ao Instituto Nacional de Previdência Social (INPS). Aos excluídos do mercado, restava recorrer aos poucos serviços oferecidos por secretarias estaduais ou municipais, ou ainda à filantropia, e, dessa forma, incorporar o conjunto da população brasileira ao SUS foi a grande inovação em termos de política pública de saúde no Brasil (Cohn e Elias, 2003).

Desenhar e implementar a arquitetura desse sistema, dentro de um processo de gestão compartilhada entre os três entes federados - União, estados e municípios —, demandou, e continua demandando, um esforço criativo. O Pacto Federativo que vem sendo desenvolvido em torno do setor implicou concertação das responsabilidades sanitárias, de gestão e de financiamento do sistema, além da organização de processos decisórios internos ao setor que não podem ser realizados sem a participação das três esferas de governo e sem a efetiva participação da sociedade, representada nos conselhos e na conferência de saúde, com representação de usuários, trabalhadores e prestadores de serviços (Campos et al., 2007).

As Comissões Intergestores Bipartites, que reúnem os gestores municipais e estaduais no âmbito de cada unidade federada, e a Comissão Intergestores Tripartite, que reúne os representantes dos diversos níveis de gestão do sistema, representados pelo Ministério da Saúde, Conselho Nacional de Secretários Estaduais (Conass) e Conselho Nacional de Secretários Municipais de Saúde (Conasems), são as instâncias gestoras do sistema, onde todas as deliberações obedecem ao princípio do consenso (Cohn e Elias, 2003).

O esforço para aprimorar esse arranjo organizacional passou por diversas etapas e momentos, o mais recente deles foi o Pacto pela Saúde. Este instrumento de gestão abrange três dimensões: o Pacto pela Vida, o Pacto de Gestão e o Pacto em Defesa do SUS. O primeiro, focado na gestão por resultados, com definição de compromissos com objetivos e metas a serem cumpridos pelos gestores em cada nível de governo; o segundo, voltado para a permanente discussão sobre a distribuição de responsabilidades entre os entes federados; e o último, representando um compromisso político em defesa do sistema, com vistas a sua institucionalização como política de Estado e não de governos (Brasil, 2006).

O Decreto 7.508/2011 introduz novos desafios ao processo de organização do SUS com a reintrodução do tema da regionalização, ou seja, da necessidade de adoção de um modelo de organização dos serviços em bases regionais. A tomada de decisões no âmbito do sistema 
impõe a estruturação de um novo espaço de gestão (os Colegiados Intergestores Regionais) e a introdução de um novo instrumento resultante da concertação feita neste nível do sistema — o Contrato de Organização da Ação Pública (Coap). A imagem-objetivo a ser perseguida é a da gestão e financiamento por resultados e a definição de responsabilidade entre os gestores quanto ao alcance desses resultados, com a possibilidade de adoção de medidas legais sobre gestores que não cumprirem metas estabelecidas (Brasil, 2011).

Nesse contexto, a gestão de unidades hospitalares, pela sua enorme complexidade, custo e importância na rede de atenção à saúde, tem merecido um olhar especial e se tornado objeto de proposições. Entre as propostas, a que ganhou maior destaque foi a da criação de Organizações Sociais de Saúde (OSS), que teve seu início por decisão do governo do estado de São Paulo. Essas novas figuras jurídicas, derivadas da reforma administrativa de 1995, delegam a organizações públicas não estatais a tarefa de gerenciar, em nome do poder público, unidades hospitalares de propriedade pública estatal. A relação dessas organizações públicas é mediada por um contrato de gestão que estabelece objetivos, metas e compromissos entre as partes (Barbosa e Elias, 2010).

Além desse modelo, o setor saúde vem trabalhando com outras possibilidades, entre elas, a de criação de parcerias público-privadas (PPP). O sistema conta hoje com uma unidade hospitalar construída nesta modalidade, no estado da Bahia. Nesse formato de parceria, o setor privado constrói e equipa o hospital, realiza seu gerenciamento por meio de uma OSS e explora esse serviço por um período de tempo, por meio de instrumento de concessão. Ao final desse período, a unidade e todos os seus equipamentos são incorporados ao patrimônio público (Cotta, 2012; Brasil, 2004).

Outro instrumento que vem sendo desenvolvido, mas ainda com baixa implementação, é o de criação de fundações estatais, defendido pelo, à época, ministro da saúde José Gomes Temporão. Esse modelo objetivava dar maior autonomia aos gerentes de unidades hospitalares para contratação de pessoal e aquisição de bens e serviços, com mais agilidade do que aquelas típicas da administração direta. A experiência de implantação dessa figura jurídica tem sido desenvolvida também na Bahia e tem sido empregada para resolver o problema da precariedade de vínculos enfrentada no âmbito da Estratégia de Saúde da Família (Bahia, 2012).

Uma iniciativa de incentivo à inovação é a criação do Prêmio InovaSUS, que representa uma janela de oportunidades para divulgação de experiências locais que representem esforço de melhoria na gestão do sistema. As três últimas edições do prêmio dedicaram espaço ao tema dos recursos humanos em saúde (Gestão do Trabalho, Carreira e Estudo sobre Força de Trabalho). Tendo em vista que o prêmio surge como iniciativa da Secretaria de Gestão do Trabalho e Educação em Saúde, é natural que o tema dominante seja este. Na maioria dos casos, trata-se de experiência de aperfeiçoamento de serviços e ações, de natureza incremental, sem repercussão sobre o conjunto do sistema.

Diante do quadro que apresenta a literatura, parece que o conceito que melhor traduz o conjunto de experiências de inovação no setor saúde é o de eficiência, ou seja, do melhor uso possível dos recursos disponíveis. A nova gestão pública, como já referenciado, tem seu 
conjunto de proposições focadas nesta busca de aumento dos níveis de eficiência. A descentralização, seja como forma de transferência de recursos e responsabilidade entre entes federados, seja como devolução à sociedade de tarefas exercidas exclusivamente por organismos do Estado, busca o alcance de melhores resultados, ao menor custo possível, portanto, não representa um fim em si mesmo.

A descentralização, na medida em que transfere recursos e responsabilidades no interior do SUS, abre espaço para a implementação de experiências inovadoras no sistema. A adoção de Organizações Sociais deu-se a partir de decisão dos gestores estaduais, assim como a organização das Redes de Atenção à Saúde não poderá se dar sem concurso dos entes municipais neste processo. Descentralização, democratização e eficiência são medidas com poder sinérgico no desenvolvimento do SUS e na consequente abertura a espaços para inovação.

Este breve resumo mostra o esforço realizado pelo SUS para buscar a inovação no processo de gestão e gerenciamento de sistemas e serviços. Esforço que se faz acompanhar de formulação também no âmbito da Gestão do Cuidado, com a proposta de construção de redes regionalizadas de atenção à saúde. Essa proposta busca somar eficiência na gestão, com a operação do sistema em redes de atenção, baseadas no princípio de ganhos de escala, na qualidade na prestação de serviços e ações mediante a adoção de Linhas de Cuidado, baseadas em protocolos clínicos e gerenciais, voltados para padronização de condutas e consequente diminuição de risco de iatrogenia e do desperdício de recursos (Mendes, 2010).

\section{Método}

O presente estudo é do tipo qualitativo-descritivo e busca analisar o conjunto das experiências, no âmbito dos serviços de saúde, que foram premiadas nas 16 edições do Concurso Inovação na Administração Pública Federal, no período de 1995 a 2011.

O estudo teve como base de dados os casos premiados no Concurso Inovação na Gestão Pública Federal que é promovido há 16 anos e representa um estímulo à disseminação de soluções inovadoras em organizações do governo federal. Desde 1996, recebeu 1.309 inscrições, tendo premiado 301 iniciativas. Promovido pela Enap com a colaboração do Ministério do Planejamento, Orçamento e Gestão, esse concurso tem como um dos principais objetivos a valorização de equipes de servidores públicos que aplicam esforços, tempo, recursos e criatividade em suas atividades, a fim de gerar inovação. As áreas premiadas são as mais variadas possíveis. Neste estudo, analisaram-se somente as experiências vencedoras na área de saúde, que totalizaram 19 casos.

Os dados foram coletados no banco de experiências hospedado no site da Enap. Foram selecionados todos os casos (19) relacionados com o processo de inovação na área de saúde. Após esse processo, todos os casos foram lidos, organizados e analisados em um quadro de acordo com as dimensões construídas para o alcance dos objetivos deste trabalho. 
Utilizaram-se para isso as seguintes dimensões: identificação dos casos, objetivos, tipo, abrangência e resultados da inovação (Tidd, Bessant e Pavitt, 2008; OCDE, 2006). Neste trabalho, classificaram-se as experiências em três desses tipos, que são as inovações de processo, as inovações de produto, incluindo serviços, e as inovações organizacionais, por serem tipos mais comuns nas organizações públicas onde floresceram as experiências aqui analisadas.

A dimensão identificação do trabalho se faz necessária, tendo em vista que em sua maioria representa adequadamente o campo semântico e de conhecimento da área de inovação, assim como os objetivos que são parâmetros que auxiliam para essa mesma compreensão. Em relação à abrangência, classificou-se seu espaço de desenvolvimento em: local, regional ou nacional, como forma de se avaliar o nível de repercussão das ações premiadas que podem implicar ações pontuais em uma única organização local ou mesmo abranger múltiplas unidades de uma mesma organização que tenham repercussão em nível regional ou até mesmo nacional, o que certamente também implica inovações de maior dimensão. Por último, descreveram-se os resultados de cada experiência para uma avaliação mais específica do que se considerou inovação no setor de saúde.

Assim, entende-se que as dimensões formuladas para a análise dos casos selecionados fornecem subsídios suficientes para traçar o perfil das experiências de inovação na área de saúde pública no Brasil.

\section{Resultados e discussão}

Para a análise e alcance dos objetivos deste trabalho, apresenta-se a seguir um quadro que sintetiza as 19 experiências na área de saúde premiadas entre 1995 e 2011, organizadas conforme o método estabelecido de identificação dos casos, objetivos, tipo, abrangência e seus resultados. Na sequência, o quadro 1 é discutido e analisado.

\section{Quadro 1}

Experiências premiadas nos 16 concursos de inovação entre 1995 e 2011

\begin{tabular}{|c|c|c|}
\hline Identificação dos casos & Objetivos/Tipo/Abrangência & Resultados \\
\hline $\begin{array}{l}\text { 1. Sistema de } \\
\text { controle logístico } \\
\text { de medicamentos } \\
\text { antirretrovirais (Siclom) }\end{array}$ & $\begin{array}{l}\text { Fazer o gerenciamento logístico dos } \\
\text { medicamentos antirretrovirais (ARV) e } \\
\text { de aprimoramento da qualificação da } \\
\text { dispensação. } \\
\text { v Processo e serviço } \\
\text { v Nacional }\end{array}$ & $\begin{array}{l}\text { - Padronização das ações de controle dos } \\
\text { medicamentos - ARV: consumo, estoques e } \\
\text { validade. } \\
\text { v Controle individual dos pacientes na dispensação } \\
\text { por categorias de usuários. } \\
\text { v Acompanhamento da incidência das epidemias. }\end{array}$ \\
\hline $\begin{array}{l}\text { 2. A Estratégia de Saúde } \\
\text { da Família (ESF) }\end{array}$ & $\begin{array}{l}\text { - Reorganizar o modelo de atenção } \\
\text { tradicional curativo, centrado na doença. } \\
\text { v Processo, serviço e organizacional. } \\
\text { v Nacional }\end{array}$ & $\begin{array}{l}\text { Os resultados são apresentados por meio de } \\
\text { alguns indicadores, porém somente na forma } \\
\text { conceitual, sem medidas quantitativas, ancorados } \\
\text { em estudos que avaliaram a ESF. }\end{array}$ \\
\hline
\end{tabular}




\begin{tabular}{|c|c|c|}
\hline Identificação dos casos & Objetivos/Tipo/Abrangência & Resultados \\
\hline $\begin{array}{l}\text { 3. Oposições a pedidos } \\
\text { de patente de } \\
\text { medicamentos }\end{array}$ & $\begin{array}{l}\text { Apresentar subsídio a exame dos } \\
\text { pedidos de patente da área farmacêutica } \\
\text { junto ao Instituto Nacional de } \\
\text { Propriedade Industrial (Inpi), de modo } \\
\text { a impedir a concessão de patentes } \\
\text { para medicamentos de interesse do } \\
\text { Ministério da Saúde (MS). } \\
\text { v Processo } \\
\text { v Nacional }\end{array}$ & $\begin{array}{l}\text { Diminuição do preço de medicamentos, por } \\
\text { exemplo, do Tenofovir, cuja redução foi de 73\% } \\
\text { de } 2003 \text { a } 2009 \text {. } \\
\text { v Competência desenvolvida pelo MS na tecnologia } \\
\text { de oposição a pedido de patente. }\end{array}$ \\
\hline $\begin{array}{l}\text { 4. Revisão dos } \\
\text { procedimentos } \\
\text { de pós-registro de } \\
\text { medicamentos }\end{array}$ & $\begin{array}{l}\text { Implementar procedimentos } \\
\text { inovadores de avaliação do pós- } \\
\text { registro de medicamentos, para a } \\
\text { sua desburocratização, celeridade e } \\
\text { previsibilidade. } \\
\text { v Processo } \\
\text { v Nacional }\end{array}$ & $\begin{array}{l}\text { Maior previsibilidade nas ações de pós-registro. } \\
\text { Redução no número de indeferimentos nos } \\
\text { pedidos de pós-registro. } \\
\text { Análise de } 100 \% \text { no grupo de medicamentos } \\
\text { novos. }\end{array}$ \\
\hline $\begin{array}{l}\text { 5. Sistema de pré- } \\
\text { qualificação de marcas } \\
\text { e produtos médico- } \\
\text { hospitalares do Instituto } \\
\text { Nacional de Câncer } \\
\text { (Inca) }\end{array}$ & $\begin{array}{l}\text { Assegurar a compra do material peculiar } \\
\text { às necessidades do Inca em condições } \\
\text { especiais, diante da Lei no 8.666/1993. } \\
\text { v Processo } \\
\text { v Nacional }\end{array}$ & $\begin{array}{l}\text { - Garantia da excepcionalidade que objetiva } \\
\text { a segurança do paciente sem ferir a Lei no } \\
\text { 8.666/1993. }\end{array}$ \\
\hline $\begin{array}{l}\text { 6. Vigilância à saúde } \\
\text { da criança e do } \\
\text { adolescente }\end{array}$ & $\begin{array}{l}\text { Reduzir o número de hospitalizações e } \\
\text { óbitos entre crianças e adolescentes } \\
\text { (0 a } 18 \text { anos); } \\
\text { v Promover adequado acompanhamento } \\
\text { aos egressos hospitalares } \\
\text { v Processo e serviço } \\
\text { v Local }\end{array}$ & $\begin{array}{l}\text { Educação continuada para aperfeiçoamento dos } \\
\text { profissionais em promoção e prevenção. } \\
\text { v Criação de protocolos para o atendimento das } \\
\text { cinco causas mais comuns de hospitalização. } \\
\text { v Mudança da política de distribuição de } \\
\text { medicamentos entre os egressos hospitalares e } \\
\text { para a população com asma. }\end{array}$ \\
\hline $\begin{array}{l}\text { 7. Programa Trabalhando } \\
\text { com Parteiras } \\
\text { Tradicionais }\end{array}$ & $\begin{array}{l}\text { Melhorar a assistência ao parto } \\
\text { domiciliar realizado por parteiras } \\
\text { tradicionais, com reconhecimento dos } \\
\text { profissionais da assistência obstétrica, e } \\
\text { articulações dessas ações junto ao SUS. } \\
\text { v Processo e serviço } \\
\text { v Nacional }\end{array}$ & $\begin{array}{l}\text { - Aumento do cadastramento das parteiras. } \\
\text { v Aumento de notificação dos partos domiciliares. } \\
\text { v Aumento do encaminhamento para assistência } \\
\text { pré-natal. } \\
\text { v Adoção de técnicas mais seguras para a realização } \\
\text { do parto. }\end{array}$ \\
\hline $\begin{array}{l}\text { 8. Projeto Bombeiros da } \\
\text { Vida }\end{array}$ & $\begin{array}{l}\text { Veduzir a mortalidade infantil por meio } \\
\text { do estímulo da prática da amamentação } \\
\text { e a doação do leite excedente. } \\
\text { v Processo e serviço } \\
\text { v Regional }\end{array}$ & $\begin{array}{l}\text { Aumento de } 90 \% \text { no volume de leite humano } \\
\text { coletado no DF. } \\
\text { Aumento de } 15 \text { para } 84 \text { atendimentos } \\
\text { emergenciais na assistência pré-hospitalar } \\
\text { relacionados com a dificuldade na alimentação no } \\
\text { período de } 1998-2001 \text {. }\end{array}$ \\
\hline
\end{tabular}




\begin{tabular}{|c|c|c|}
\hline Identificação dos casos & Objetivos/Tipo/Abrangência & Resultados \\
\hline $\begin{array}{l}\text { 9. Registro eletrônico } \\
\text { do atendimento } \\
\text { ambulatorial: mais um } \\
\text { passo na consolidação } \\
\text { do prontuário } \\
\text { eletrônico do paciente } \\
\text { no HC/POA }\end{array}$ & $\begin{array}{l}\text { - Informatizar o atendimento ambulatorial } \\
\text { para integrar as informações clínicas do } \\
\text { prontuário do paciente } \\
\text { v Processo e serviço } \\
\text { v Local }\end{array}$ & $\begin{array}{l}\text { - Aumento de 5,7\% nas consultas. } \\
\text {. Aumento de } 235 \% \text { da média mensal de } \\
\text { consultas ao prontuário eletrônico. } \\
\text {. Obtenção de diferentes indicadores de avaliação } \\
\text { da qualidade assistencial (estrutura, processo e } \\
\text { resultados). } \\
\text { - Aumentou o nível de percepção de qualidade } \\
\text { (ótima/boa) do atendimento ambulatorial pelos } \\
\text { pacientes de } 70,7 \% \text { para } 88,8 \% \text { no período } \\
\text { analisado. }\end{array}$ \\
\hline $\begin{array}{l}\text { 10. Cadastramento de } \\
\text { pré-projetos pela } \\
\text { internet }\end{array}$ & $\begin{array}{l}\text { Agilizar e simplificar o processo de } \\
\text { apresentação de propostas de projetos } \\
\text { ao Ministério da Saúde. } \\
\text { v Processo } \\
\text { v Nacional }\end{array}$ & $\begin{array}{l}\text { - Maior transparência e controle social. } \\
\text { - Aprimoramento da metodologia de apresentação } \\
\text { de propostas. } \\
\text { v Redução nos gastos na produção de projetos. }\end{array}$ \\
\hline $\begin{array}{l}\text { 11. Sistema de gestão } \\
\text { financeira e de } \\
\text { convênios (Gescon) }\end{array}$ & $\begin{array}{l}\text { Organizar e otimizar a gestão financeira } \\
\text { e de convênios do Fundo Nacional de } \\
\text { Saúde (FNS). } \\
\text { v Processo } \\
\text { v Nacional }\end{array}$ & $\begin{array}{l}\text { (descentralização, racionalidade administrativa e } \\
\text { maior transparência operacional). } \\
\text { v Informatização das atividades de convênios. } \\
\text { v Análise da prestação de contas de todos os } \\
\text { convênios, sem atrasos. }\end{array}$ \\
\hline $\begin{array}{l}\text { 12. Projeto Hospitais } \\
\text { Sentinela: uma } \\
\text { estratégia de } \\
\text { vigilância para pós- } \\
\text { comercialização de } \\
\text { produtos de saúde. }\end{array}$ & $\begin{array}{l}\text { Criar condições para fortalecer, ampliar } \\
\text { e consolidar uma rede de serviços de } \\
\text { saúde-sentinela para favorecer ações } \\
\text { de vigilância sanitária de serviços e } \\
\text { produtos de saúde pós-comercialização. } \\
\text { v Processo } \\
\text { v Nacional }\end{array}$ & $\begin{array}{l}\text { Redução de custo de informações sobre a } \\
\text { qualidade e segurança de produtos sujeitos à } \\
\text { vigilância sanitária. } \\
\text { v Rapidez da comunicação entre os participantes da } \\
\text { rede. } \\
\text { v Incorporação do gerenciamento de risco e } \\
\text { notificação de eventos adversos. }\end{array}$ \\
\hline $\begin{array}{l}\text { 13. Saúde e Prevenção: } \\
\text { um passo para a } \\
\text { melhoria da qualidade } \\
\text { de vida }\end{array}$ & $\begin{array}{l}\text { - Melhorar a qualidade de vida dos } \\
\text { servidores, por meio de uma política } \\
\text { de qualidade total, para a obtenção de } \\
\text { melhoria da qualidade do trabalho. } \\
\text { - Processo } \\
\text { v Local }\end{array}$ & $\begin{array}{l}\text { Melhoria da qualidade de vida e de trabalho dos } \\
\text { servidores. } \\
\text { - Otimização da relação custo/benefício do } \\
\text { investimento em saúde no trabalho. } \\
\text { vaior eficiência no atendimento médico dos } \\
\text { servidores. }\end{array}$ \\
\hline $\begin{array}{l}\text { 14. Treinamento de } \\
\text { gerência regional }\end{array}$ & $\begin{array}{l}\text { - Capacitar os técnicos das diretorias } \\
\text { regionais de saúde (Dires), da } \\
\text { Secretaria Estadual de Saúde de São } \\
\text { Paulo e das Secretarias de Saúde dos } \\
\text { municípios em gestão semiplena, para } \\
\text { o desenvolvimento de atividades de } \\
\text { avaliação e controle. } \\
\text { v Processo } \\
\text { v Regional }\end{array}$ & $\begin{array}{l}\text { Vonstrução de um novo marco conceitual sobre } \\
\text { avaliação e controle. } \\
\text { vstímulo ao intercâmbio de práticas e à } \\
\text { articulação regional. } \\
\text { veciclagem dos auditores federais, oriundos do } \\
\text { antigo Inamps. } \\
\text { v Estabelecimento, pela SES-SP, de parâmetros para } \\
\text { o atendimento ambulatorial. }\end{array}$ \\
\hline
\end{tabular}




\begin{tabular}{|c|c|c|}
\hline Identificação dos casos & Objetivos/Tipo/Abrangência & Resultados \\
\hline $\begin{array}{l}\text { 15. Redução da taxa de } \\
\text { cancelamento de } \\
\text { cirurgias por meio } \\
\text { da otimização do } \\
\text { processo assistencial }\end{array}$ & $\begin{array}{l}\text { Reduzir a taxa de cancelamento de } \\
\text { cirurgias no Hospital de Clínicas de Porto } \\
\text { Alegre. } \\
\text { v Processo } \\
\text { v Local }\end{array}$ & $\begin{array}{l}\text { Vransparência das listas de espera dos pacientes } \\
\text { que aguardam cirurgias. } \\
\text { v Respeito ao tempo mínimo para realização de } \\
\text { cirurgia. } \\
\text { v Uso do protocolo de avaliação pré-operatória. } \\
\text { v Otimização das salas cirúrgicas. }\end{array}$ \\
\hline $\begin{array}{l}\text { 16. Consultas médicas: } \\
\text { oferta, demanda, } \\
\text { mudança cultural e o } \\
\text { fim das filas }\end{array}$ & $\begin{array}{l}\text { Desenvolver um processo de marcação } \\
\text { de consultas que diminuísse as filas do } \\
\text { hospital do Centro Técnico Aeroespacial } \\
\text { (CTA). } \\
\text { v Processo } \\
\text { v Local }\end{array}$ & $\begin{array}{l}\text { Vxtinção das filas para marcar consultas, sem que } \\
\text { a relação oferta/demanda fosse alterada. } \\
\text { vova sistemática de marcação de consultas } \\
\text { caracterizada por: transparência de critérios, } \\
\text { democratização do acesso e compromisso formal. } \\
\text { v Mudança comportamental na motivação de } \\
\text { procurar pelo atendimento médico. }\end{array}$ \\
\hline $\begin{array}{l}\text { 17. Programa de Melhoria } \\
\text { do Atendimento } \\
\text { aos Usuários do } \\
\text { Ambulatório Maria da } \\
\text { Glória (Fac. Med. do } \\
\text { Triângulo Mineiro) }\end{array}$ & $\begin{array}{l}\text { Promover a melhoria do ambiente físico } \\
\text { para a humanização do atendimento no } \\
\text { Ambulatório Maria da Glória. } \\
\text { vrocesso e organizacional } \\
\text { v Local }\end{array}$ & $\begin{array}{l}\text { - Aumento da satisfação dos clientes, resultante de } \\
\text { melhor atendimento prestado pelos servidores do } \\
\text { ambulatório. } \\
\text { velhorias introduzidas no ambiente físico do } \\
\text { ambulatório, benéficas tanto aos clientes internos } \\
\text { como externos. }\end{array}$ \\
\hline $\begin{array}{l}\text { 18. Banco de Preços } \\
\text { Praticados na Área } \\
\text { Hospitalar (BPPH) - } \\
\text { Ministério da Saúde }\end{array}$ & $\begin{array}{l}\text { Dar transparência a preços de } \\
\text { medicamentos, materiais, insumos e } \\
\text { serviços utilizados em hospitais da rede } \\
\text { pública. } \\
\text { v Aumentar o leque de fornecedores } \\
\text { nacionais e internacionais que poderão } \\
\text { interagir junto aos hospitais públicos, } \\
\text { filantrópicos e privados. } \\
\text { v Processo } \\
\text { v Nacional }\end{array}$ & $\begin{array}{l}\text { Fornecimento de informações inéditas às } \\
\text { instituições de regiões remotas do país, que } \\
\text { ficariam dependentes dos fornecedores da região. } \\
\text { Incentivo aos fornecedores para ampliarem o seu } \\
\text { mercado. } \\
\text { V Troca de informações e experiências entre os } \\
\text { participantes em outras áreas da gestão hospitalar. }\end{array}$ \\
\hline $\begin{array}{l}\text { 19. Comitês } \\
\text { Coordenadores } \\
\text { de Auditorias por } \\
\text { Especialidades } \\
\text { Médicas }\end{array}$ & $\begin{array}{l}\text { Fortalecer o Sistema Nacional de } \\
\text { Auditoria do SUS por meio da } \\
\text { capacitação do Depto. Nacional de } \\
\text { Auditoria do SUS (Denasus), que deve } \\
\text { ser o órgão central da auditoria. } \\
\text { v Processo e serviço } \\
\text { v Nacional }\end{array}$ & $\begin{array}{l}\text { Vlaboração de um roteiro de auditoria mais } \\
\text { acurado e completo, permitindo resultados mais } \\
\text { efetivos. } \\
\text { v Possibilidade de melhor regulamentar os serviços } \\
\text { de saúde, por meio de alterações na legislação. } \\
\text { v Capacitação do auditor e valorização desse } \\
\text { profissional. }\end{array}$ \\
\hline
\end{tabular}

Fonte: Elaborado pelos autores com base em Enap (2012).

A identificação dos trabalhos premiados bem como seus objetivos mostram o vetor de direção do processo de inovação no setor público, o que pode ser observado no quadro 1 . Pode-se verificar que são basicamente inovações caracterizadas por pequenas mudanças em estruturas de serviços ou nos processos de trabalho.

No que diz respeito ao tipo do processo, a análise do quadro 1 permite classificar os diversos objetivos das experiências premiadas no concurso de inovação em: 
a) inovação de processo, expressa nos casos analisados como: redesenho, simplificação e informatização de processos, desburocratização, avaliação e controle administrativos, garantia de transparência e interpretação (brechas legais) da legislação de maneira a atender a especificidades do setor de saúde;

b) inovação organizacional, expressa pelo desenvolvimento de novos arranjos e estruturas institucionais para a provisão de serviços e ações de saúde, tal como a melhoria de atendimento aos usuários de um ambulatório;

c) inovação de serviço, expressa por iniciativas de ação direta para a melhoria da qualidade dos serviços prestados, como comitês coordenadores de autorias por especialidades médicas.

Esses tipos de inovação estão alinhados com os tipos definidos na literatura sobre inovação. Como propõem o Manual de Oslo (OCDE, 2003) e Tidd, Bessant e Pavitt (2008), a inovação é entendida como qualquer tipo de mudança ou novos desenvolvimentos em: produtos, serviços, processos, marketing, posição e paradigma. Neste trabalho, as dimensões de inovação de marketing, inovação de posição e inovação de paradigma não são aplicáveis porque nos casos analisados não foram encontrados elementos substantivos que fundamentem classificações nessas dimensões.

Nos casos analisados, o que ocorre são ações de comunicação e divulgação de ações governamentais. Nesta análise, recorrer ao conceito de inovação em marketing seria reduzir marketing a comunicação. Já as inovações de posições são mudanças no contexto nas quais produtos e serviços são introduzidos; e inovações de paradigma são mudanças nos modelos mentais que direcionam o que a organização faz (Tidd, Bessant e Pavitt, 2008), não fazendo sentido utilizar esses conceitos para analisar os casos do presente trabalho.

No tipo inovação de processos, 14 experiências foram encontradas no total de 19 analisadas, tais como gerenciamento logístico e revisão de procedimentos de gerenciamento de medicamentos, informatização de atendimento laboratorial, garantia de transparência a preços de medicamentos, material, insumos e serviços hospitalares. Daí pode-se inferir que a inovação em processos é a mais comum no conjunto das organizações que submeteram suas experiências ao concurso de inovação.

Já no tipo inovação organizacional, foram encontrados somente dois casos que são o de Estratégia de Saúde da Família e o de melhoria do ambiente físico em uma unidade ambulatorial, e esses dois casos também se configuram como inovação de processo. Esse resultado enseja algumas questões: seria esse tipo de inovação mais complexo, oneroso e de difícil implementação? Haveria ambiente de inovação propício no setor de saúde pública a tal tipo de mudança? O quadro teórico apresentado sobre inovação não responde a tais questionamentos.

$\mathrm{Na}$ análise do tipo inovação em serviços, foram encontrados cinco casos de promoção de saúde: estímulo à prática da amamentação, acompanhamento de egressos hospitalares, assistência ao parto domiciliar por parteiras, rede de saúde-sentinela e melhoria da qualidade de vida de servidores. Considerou-se aqui como promoção de saúde a prestação de serviços 
que geraram melhorias diretas ao público externo ou interno dessas organizações participantes do referido concurso. É um dado relativamente baixo de ações que parecem não responder ainda aos desafios atuais de inovações em saúde e que requerem novos instrumentos para o enfrentamento das grandes necessidades de saúde da população (Beinare e McCarthy, 2011; Hennala, Parjanen e Uotila, 2011; Brasil, 2009a).

Na dimensão abrangência, o quadro 1 apresenta 11 experiências premiadas que tiveram repercussão em nível nacional, seis se restringiram ao nível local e duas tiveram reflexos em âmbito regional. Essa distribuição pode ser explicada pelo fato de o concurso ser promovido somente em nível federal. O fato de quase 58\% de casos terem decorrências em âmbito nacional pode ser visto como algo positivo, no sentido de que seus resultados podem ser mais facilmente difundidos para outras organizações de governo. Como exemplos, podem-se enumerar nessa dimensão os sistemas de controle logístico de medicamentos antirretrovirais; a Estratégia de Saúde da Família; o sistema de gestão financeira de convênios; o projeto hospitais-sentinela; e o banco de preços praticados na área hospitalar.

Os casos classificados no nível local caracterizam-se, de maneira geral, por mudanças na forma de marcação de consultas e atendimentos em ambulatórios ou hospitais, algo que poderia ser difundido para os demais níveis de abrangência. Isso mostra que há um espaço significativo para a difusão de inovações nos serviços de saúde, especialmente no SUS (Farias et al., 2011; Santos e Andrade, 2009).

A análise da dimensão resultados apresentados no quadro 1 permite classificá-los em:

a) otimização de processos de trabalho, como: padronização de ações de controle de medicamentos; redução no número de pedidos indeferidos no pós-registro de medicamentos; gestão mais precisa de convênios firmados no Fundo Nacional de Saúde (FNS); redução de custo na obtenção de informações relativas à segurança de produtos sujeitos à vigilância sanitária; roteiro de auditoria mais acurado pelas coordenadorias de especialidades médicas; redução nos gastos na produção de projetos ao MS por meio do cadastramento de préprojetos pela internet. Como se pode perceber, esse bloco de experiências se concentra na eficiência operacional, o que mais tem ocorrido no conjunto dos casos analisados.

b) aumento da satisfação do usuário, percebida, por exemplo, nas seguintes situações: consolidação do prontuário eletrônico do paciente no HC/POA; melhoria da qualidade de vida dos servidores numa experiência local; extinção das filas para marcar consultas médicas no hospital do CTA; melhor atendimento prestado pelos servidores do ambulatório Maria da Glória. Essas inovações podem melhorar os níveis de serviço que se constituem em benefício social e também podem melhorar a sua produtividade, pois as organizações de serviço público precisam inovar tanto para melhorar a eficiência quanto para aumentar a satisfação do usuário do serviço (Salazar e Holbrook, 2004).

c) aquisição de competências organizacionais, evidenciadas, por exemplo, nos seguintes casos: oposição a pedidos de patente de medicamentos; aprimoramento da metodologia de apresentação de propostas para cadastramento de pré-projetos pela internet; construção de um novo marco conceitual sobre avaliação e controle na gestão semiplena; disseminação 
de informações inéditas a instituições de regiões remotas do país com base no BPPH-MS; aprimoramento da regulamentação dos serviços de saúde, a partir do fortalecimento dos comitês coordenadores de auditorias por especialidades médicas.

Esse conjunto de resultados mostra que as inovações não se resumiram a inovações incrementais, algumas apresentando inovações radicais (Tidd, Bessant e Pavitt, 2008). Para responder o que seria inovação nos serviços públicos, Spink (2006) afirma ser mudança substancial, qualitativa ou quantitativa nas práticas anteriores, ou seja: implantação de uma nova ação ou programa; ampliação ou consolidação das formas de acesso e diálogo entre sociedade e governo. Essa abordagem das melhores práticas pode impor um melhor método, diferente da abordagem da inovação que busca o diálogo aberto entre sociedade e governo na busca da melhoria das práticas públicas (Beinare e McCarthy, 2011). A análise deste trabalho indica que a abordagem preponderante é a das melhores práticas.

Embora ainda haja poucas pesquisas, observa-se que o processo de inovação já se difundiu na área pública, mas assumindo diferentes sentidos, ora significando processos de mudanças na gestão voltados à busca da eficiência, ora significando a democratização da ação estatal, tanto no aumento do volume de serviços oferecidos à população quanto na ampliação da participação popular na formulação, implementação e controle das políticas públicas (Beinare e McCarthy, 2011; Farah, 2010). No entanto, o que se observa na análise das experiências é que todas as inovações se concentram na busca da eficiência operacional, nenhuma delas apresentando participação social em sua concepção, em seu desenvolvimento e tampouco em sua implementação.

\section{Considerações finais}

Após a análise das experiências premiadas, constatou-se que, de um total de 301 casos ao longo de 16 anos de existência do concurso, foram encontradas apenas 19 experiências de inovações de saúde, o que é um número pequeno diante do tamanho do setor público de saúde no Brasil. É evidente que esse número de inovações poderia ser muito maior se o concurso de inovação contemplasse experiências dos serviços municipais e estaduais. Isso poderia ser uma alavanca para o incentivo ao processo de inovação no serviço público como um todo.

Ao concluir a análise, encontrou-se uma lacuna importante, pois em nenhum dos casos é possível identificar uma estratégia de sustentabilidade associada. Assim, não é possível saber como essas experiências estão atualmente. Será que seus resultados se mantêm ou até mesmo foram ampliados? Será que alguma delas não continuou em função de alguma contingência? Para conhecer mais detalhadamente cada experiência, seria necessário visitá-la in loco, fazer entrevistas e observações de campo, o que exigiria um trabalho de grande envergadura, fugindo aos objetivos deste trabalho.

Outro aspecto que deve ser destacado é o fato de que a totalidade dos trabalhos estudados se concentra na vertente gerencial, com inovações mais focadas em aspectos internos 
das organizações, voltados para a busca da eficiência operacional. Chama atenção também o fato de a maioria dos trabalhos (13) ser de inovações de processos, o que reforça o aspecto destacado anteriormente.

A fim de difundir o processo de inovação no setor público como um todo, e na área de saúde em especial, é fundamental que os governos em seus três níveis desenvolvam outras estratégias de incentivo e premiação, tendo como referência o concurso de inovação na administração pública federal. Outra sugestão é o desenvolvimento e a aplicação de um protocolo mais preciso em termos de indicadores quantitativos e qualitativos que permitam avaliações mais fidedignas da realidade de ações inovadoras.

Como agenda de pesquisa, sugere-se: investigar quais são os tipos de inovação mais comuns no setor de saúde; identificar obstáculos e potencialidades para inovação no setor de saúde pública; verificar como as experiências premiadas se encontram atualmente.

\section{Referências}

BAHIA. Fundação Estatal de Saúde da Família. Disponível em: <www.fesfsus.ba.gov.br>. Acesso em: 20 dez. 2012.

BARBOSA, Nelson B.; ELIAS, Paulo E. M. As organizações sociais como forma de gestão público/ privado. Revista Ciência e Saúde Coletiva, v. 15, n. 5, p. 483-495, ago. 2010.

BEINARE, Dace; McCARTHY, Mark. Civil society organizations, social innovation and health research in Europe. European Journal of Public Health, v. 22, n. 6, p. 889-893, nov. 2011.

BRASIL. Instituto Brasileiro de Geografia e Estatística. Indicadores sociodemográficos e de saúde no Brasil. 2009a. Disponível em: <www.ibge.gov.br/home/estatistica/populacao/indic_sociosaude/2009/ default.shtm>. Acesso em: 23 fev. 2012.

BRASIL. Ministério da Saúde. Decreto $n^{\circ}$ 7.508/2011. Disponível em: <www.planalto.gov.br/ ccivil_03/_ato2011-2014/2011/decreto/D7508.htm>. Acesso em: 15 mar. 2014.

BRASIL. Ministério da Saúde. Informações em saúde. 2009b. Estatísticas Vitais. DATASUS. Disponível em: <http://tabnet.datasus.gov.br>. Acesso em: 24 abr. 2012.

BRASIL. Ministério da Saúde. Portaria $n^{\circ}$ 399, de 22 de fevereiro de 2006. Consolidação do SUS e aprova as Diretrizes Operacionais. Disponível em: < http://dtr2001.saude.gov.br/sas/PORTARIAS/ Port2006/GM/GM-399.htm>. Acesso em: 20 maio 2013.

BRASIL. Presidência da República. Lei no 11.079, de 30 de dezembro de 2004. Institui normas para contratação de parceria público/privado na administração pública. Disponível em: <www.planalto. gov.br/ccivil_03/_ato2004-2006/2004/lei/111079.htm>. Acesso em: 20 maio 2013.

CAMPOS, Gastão W. S. et al. (Org.). Tratado de saúde coletiva. São Paulo: Hucitec; Rio de Janeiro: Fiocruz, 2007. 
COHN, Amélia; ELIAS, Paulo E. M. Saúde no Brasil: políticas e organização de serviços. São Paulo: Cortez, 2003.

COTTA, Elaine. Sai do papel a primeira PPP do setor saúde no Brasil. Disponível em: <www.brasileconomico.com.br>. Acesso em: 26 abr. 2012.

CUNNINGHAM, Paul. Innovation in the health sector: case study analysis. 2005. Disponível em: <www.step.no/publin/>. Acesso em: 3 dez. 2012.

DAMANPOUR, Fariborz; WISCHNEVSKY, Daniel J. Research on innovation in organizations: distinguishing innovation-generating from innovation-adopting organizations. Journal Engineering and Technology Management, v. 23, n. 4, p. 269-291, set. 2006.

EARL, Louise. Innovation and change in the public sector: a seeming oxymoron, statistics Canada. Sieid. 2002. Disponível em: <http://publications.gc.ca/Collection/Statcan/88F0006X/88F0006X IE2002001.pdf>. Acesso em: 20 mar. 2012.

ENAP. Concurso de inovação na administração pública federal. Disponível em: < http://inovação. enap.gov.br>. Acesso em: 20 abr. 2012.

FARAH, Marta F. S. Gestão pública municipal e inovação no Brasil. In: ANDREWS, Christina W.; BARIANI, Edison (Org.). Administração pública no Brasil: breve história política. São Paulo: Unifesp, 2010.

FARAH, Marta F. S. Inovação e governo local no Brasil contemporâneo. In: JACOBI, Pedro; PINHO, José A. (Org.). Inovação no campo da gestão pública local: novos desafios, novos patamares. São Paulo: FGV Editora, 2006.

FARIAS, Josivania S. et al. Adoção de prontuário eletrônico do paciente em hospitais universitários de Brasil e Espanha. A percepção de profissionais de saúde. Rev. Adm. Pública, Rio de Janeiro, v. 45, n. 5, p. 1303-1326, set./out. 2011.

GALLOUJ, Faïz; DJELLAL, Faridah. Introduction: filling the innovation gap in the service economy: a multidisciplinary perspective. In.: GALLOUJ, Faïz; DJELLAL, Faridah. The handbook of innovation and services. Cheltenham, UK: Edward Elgar, 2010.

GALLOUJ, Faïz; SAVONA, Maria. Innovation in services: a review of the debate and a research agenda. Journal of Evolutionary Economics, v. 19, n. 2, p. 149-172, 2009.

GALLOUJ, Faïz; WINDRUM, Paul. Services and services innovation. Journal of Evolutionary Economics, v. 19, n. 2, p. 141-148, 2009.

HALVORSEN, Thomas et al. Innovation in public sector: on the differences between public sector and private sector innovation. 2005. Disponível em: <www.step.no/publin/> . Acesso em: 3 dez. 2012. HENNALA, Lea; PARJANEN, Satu; UOTILA, Tuomo. Challenges of multi-actor involvement in the public sector front-end innovation processes: constructing an open innovation model for developing well-being services. European Journal of Innovation Management, v. 14, n. 3, p. 364-387, 2011. 
KLERING, Luis R.; ANDRADE, Jackeline A. Inovação na gestão pública: compreensão do conceito a partir da teoria e da prática. In: JACOBI, Pedro; PINHO, José A. (Org.). Inovação no campo da gestão pública local: novos desafios, novos patamares. São Paulo: FGV Editora, 2006.

MENDES, Eugênio V. As Redes de Atenção à Saúde. Ciência \& Saúde Coletiva, v. 15, n. 5, p. 22972305, 2010.

MOREIRA, Marina F.; VARGAS, Eduardo R. Compras governamentais e inovação em serviços de software. In: ENCONTRO DA ANPAD, XXXIII, 2009, São Paulo. XXXIII EnAnpad. São Paulo: Editora Anpad, 2009. Disponível em: <http://anpad.org.br/evento.php?acao=trabalho\&cod_edicao_subsecao $=506 \&$ cod_evento_edicao $=45 \&$ cod_edicao_trabalho $=10864>$. Acesso em: 20 jan. 2013.

OECD. Organization for Economic Cooperation and Development. Manual de Oslo: diretrizes para coleta e interpretação de dados sobre inovação. 3. ed. Rio de Janeiro: Finep, 2006.

O'TOOLE JR., Laurence J. Implementing public innovation in networks settings. Administration \& Society, v. 29, n. 2, p. 115-138, maio 1997.

RØSTE, Rannveig. Studies of innovation in the public sector: a theorical framework. 2005. Disponível em: <www.step.no/publin/>. Acesso em: 3 dez. 2012.

SALAZAR, Monica; HOLBROOK, Adam. A debate on innovation surveys. Science and Public Policy, v. 31, n. 4, p. 254-266, ago. 2004.

SALGE, Torsten O. A behavioral model of innovative search: evidence from public hospital services. Journal of Public Administration Research and Theory, v. 21, n. 1, p. 181-210, abr. 2010.

SANTOS, Lenir; ANDRADE, Luiz O. M. SUS: o espaço da gestão inovadora e dos consensos interfederativos: aspectos jurídicos, administrativos e financeiros. Campinas: Saberes, 2009.

SPINK, Peter. A inovação na perspectiva dos inovadores. In: JACOBI, Pedro; PINHO, José A. (Org.). Inovação no campo da gestão pública local: novos desafios, novos patamares. São Paulo: FGV Editora, 2006.

TIDD, Joe; BESSANT, John; PAVITT, Keith. Gestão da inovação. Porto Alegre: Bookman, 2008.

VAN DE VEN. Andrew H. Central problems in the management of innovation. Management Science, v. 32, n. 5, p. 590-607, maio 1986.

VARGAS, Eduardo R.; ZAWISLAK, Paulo A. Inovação em serviços no paradigma da economia do aprendizado: a pertinência de uma dimensão espacial na abordagem dos sistemas de inovação. Revista de Administração Contemporânea, v. 10, n. 1, p. 139-159, jan./mar. 2006.

WALKER, Richard M.; DAMANPOUR, Fariborz; DEVECE, Carlos A. Management innovation and organizational performance: the mediating effect of performance management. Journal of Public Administration Research and Theory, v. 21, n. 2, p. 367-386, ago. 2010. 
Vicente da Rocha Soares Ferreira é doutorando em administração pela UnB. Mestre em administração pela Universidade de São Paulo (Fearp). Professor assistente da Faculdade de Administração, Ciências Contábeis e Economia da UFG. E-mail: vicenterochasf@uol.com.br.

Estela Najberg é doutora em administração pela EAESP-FGV. Professora adjunta da Faculdade de Administração, Ciências Contábeis e Economia da UFG. E-mail: estelanajberg@gmail.com.

Cintia Bragheto Ferreira é doutora em enfermagem em Saúde Pública pela Escola de Enfermagem de Ribeirão Preto da Universidade de São Paulo. Professora adjunta do Curso de Psicologia da UFG, Regional Jataí. E-mail: cintiabragheto@hotmail.com.

Nelson Bezerra Barbosa é doutor pela Faculdade de Medicina da USP. Gestor público da Secretaria de Estado da Saúde de Goiás. E-mail: nelsonbbarbosa@gmail.com.

Cândido Borges é PhD pela HEC Montréal (Canadá). Professor adjunto da Faculdade de Administração, Ciências Contábeis e Economia da UFG. E-mail: candidoborges@gmail.com. 
